\title{
Inhibition of S-phase kinase-associated protein 2-mediated p27 degradation suppresses tumorigenesis and the progression of hepatocellular carcinoma
}

\author{
MING $\mathrm{QI}^{1}$, DONGMEI LIU ${ }^{2}$, SHUHONG ZHANG ${ }^{1}$, PEIXIN HU ${ }^{1}$ and TAN SANG ${ }^{3}$ \\ Departments of ${ }^{1}$ Digestive System, ${ }^{2}$ Transfusion Center and ${ }^{3}$ Hematology, \\ Jinan Central Hospital Affiliated to Shandong University, Jinan, Shandong 250013, P.R. China
}

Received January 2, 2014; Accepted October 1, 2014

DOI: $10.3892 / \mathrm{mmr} .2015 .3156$

\begin{abstract}
In order to determine the protein expression of S-phase kinase-associated protein 2 (Skp2) and p27 ${ }^{\mathrm{kip} 1}$, and to evaluate their possible prognostic values in malignant liver cancer, tissue samples from 50 patients and 40 controls were assessed and analyzed by immunohistochemistry and western blot analysis. Positive expression of Skp2 was observed in $35(70.0 \%)$ of the hepatocellular carcinoma samples; however, the positive expression of $\mathrm{p} 27^{\mathrm{kip} 1}$ was observed in $6(15.0 \%)$ of the hepatocellular carcinoma samples. The expression of Skp2 was significantly negatively correlated with the expression of p27 $(\mathrm{P}<0.01)$. The results from Annexin V-propidium iodide staining and MTT assays indicated that interference of Skp2 significantly induced apoptosis and inhibited the proliferation of SSMC-7721 cells. In addition, the levels of endogenous p27 increased in the HepG2 and SSMC-7721 cells following transfection with siRNA specific to Skp2, suggesting that the Skp2-mediated degradation of $\mathrm{p} 27^{\mathrm{kip} 1}$ was important in the proliferation of tumor cells. The present study, therefore, provided a molecular reference for the treatment of liver cancer.
\end{abstract}

\section{Introduction}

Liver cancer is a malignant disease, which forms on the surface or within the liver, including in blood vessels or the bile duct (1-3). It is one of the most common types of solid tumor worldwide and is the third leading cause of cancer-associated mortality (4). Primary liver cancer is the most common type of malignant tumor, with poor prognosis and a high mortality rate $(5,6)$. It currently leads to 360,000 incident cases and the

Correspondence to: Mr. Ming Qi, Department of Digestive System, Jinan Central Hospital Affiliated to Shandong University, 105 Jiefang Road, Jinan, Shandong 250013, P.R. China

E-mail: qimingwork2008@163.com

Key words: S-phase kinase-associated protein, p27 $7^{\text {kip1 }}$, ubiquitin, hepatocellular carcinoma mortality of 350,000 individuals annually in China (7). The incidence and mortality rates of hepatocellular carcinoma in China account for $40-45 \%$ and $18.8 \%$ of the patients with liver cancer worldwide, respectively. Untreated patients with advanced disease usually survive $<6$ months (8) and, in 25 randomized clinical trials, the 1 and 2 year survival rates of untreated patients were between 10 and $72 \%$ and between 8 and $50 \%$, respectively (8). Thus, liver cancer is one of the major diseases affecting health.

Tumors occur in several diseases and result from disordered cell cycle regulation or loss of control over cell division. The unchecked cells may eventually form malignancies, with the activation of oncogenes or inhibition of tumor suppressor genes $(9,10)$.

The cyclin kinase inhibitor $\mathrm{p} 27^{\mathrm{kip} 1}$ is a cell-cycle regulatory protein, which is one of the most important regulators of the cell cycle (11). It interacts with cyclin-dependent kinase (CDK)2 and CDK4 to inhibit cell cycle progression at the G1 phase and is also the checkpoint of the G1-S phase transition $(12,13)$. The degradation of $\mathrm{p} 27^{\mathrm{kipl}}$ is dependent on the ubiquitin-proteasome pathway. Thus is generally triggered by phosphorylation of conserved threonine (Thr187) and subsequent ubiquitination by Skp, Cullin and F-box (SCF) complexes, and is required for cell division $(14,15)$. The ubiquitin-proteasome system is mediated by three enzymes, ubiquitin-activating enzyme, ubiquitin-conjugating enzyme and E3 ubiquitin ligase. S-phase kinase-associated protein 2 (Skp2) is one type of E3 ubiquitin ligase for recruiting a specific substrate and determining their specificity (16). Thus, Skp2 acts as an adaptor of the SCF-Skp2 complex and recognizes phosphorylated substrates, including $\mathrm{p} 27^{\mathrm{kip} 1}$ and $\mathrm{p} 21$.

Skp2 acts as an oncogene and overexpression of Skp2 is frequently observed in several types of human tumor, including lymphoma, prostate cancer, melanoma, nasopharyngeal carcinoma, pancreatic cancer and breast carcinomas, which promotes the progression and metastasis of human cancer (17-20). By comparison, p2 $7^{\mathrm{kip} 1}$, a tumor inhibitor protein, usually inhibits the progression of human cancer. In the present study, the role of the Skp2-p27 pathway in the progression of human liver cancer was investigated and the underlying mechanism was examined. Clarification of the process and progression of carcinogenesis in liver tissues 
may provide novel targets for the effective prevention of liver cancer.

\section{Materials and methods}

Liver cancer cell lines. The HepG2 and SSMC-7721 liver cancer cell lines (American Type Culture Collection, Manassas, VA, USA) were maintained in the laboratory at Jinan Central Hospital Affiliated to Shandong University (Shandong, China) and were cultured in Dulbecco's modified Eagle's medium (DMEM) with $10 \%$ fetal bovine serum (HyClone, GE Healthcare Life Sciences, Little Chalfont, UK), $1 \%$ penicillin and $1 \%$ streptomycin (Gibco-BRL, Invitrogen Life Technologies, Carlsbad, CA, USA).

Small interfering (si)RNA and antibodies. The cells were planted in 48-well plates and subsequent to a 24-h resting period, the Skp2 p45 siRNA and scramble siRNA was transfected with Lipofectamine 2000 (Invitrogen Life Technologies). Following $8 \mathrm{~h}$ of transfection, the DMEM medium was replaced and the lysates were prepared subsequent to transfection for $48 \mathrm{~h}$. The Skp2 p45 siRNA was purchased from Santa Cruz Biotechnology, Inc. (sc-36499; Dallas, TX, USA) and scramble siRNA was synthesized by Shanghai Jima Company (Shanghai, China). Rabbit polyclonal immunoglobulin G (IgG) Skp2 p45 antibody (200 $\mu \mathrm{g} / \mathrm{ml}$; sc-7164), mouse monoclonal $\mathrm{IgG}_{1}$ p27 antibody $(200 \mu \mathrm{g} / \mathrm{ml}$; sc-53906) and mouse monoclonal $\mathrm{IgG}_{1} \beta$-actin (AC-15) antibody (100 $\mu \mathrm{g} / \mathrm{ml}$; sc-69879), as well as horseradish peroxidase-conjugated goat anti-mouse secondary antibody (sc-2005) were all obtained from Santa Cruz Biotechnology, Inc.

Histology and immunohistochemistry. Liver tissue samples were obtained from Jinan Central Hospital Affiliated to Shandong University. The subjects included 50 cases of hepatocellular carcinoma and 40 paratumor tissues with an average age of $58 \pm 13$ years. The subjects were recruited from March 2011 to December 2013. The specimens were obtained during surgery. There were 52 male and 38 female patients during the experiment. Written informed consent was also obtained from the patients' families. The study was approved by the ethics committee of Jinan Central Hospital Affiliated to Shandong University (Jinan, China). The liver tissues were fixed in neutral buffered paraformaldehyde and processed for hematoxylin and eosin (H\&E) staining. Immunohistochemical staining was performed, as previously described $(21,22)$. Briefly, the paraffin-embedded sections were dewaxed, rehydrated, inhibited and incubated overnight with the primary antibodies (anti-p27 and anti-Skp2). Subsequently, the samples were incubated with goat anti-mouse and goat anti-rabbit secondary antibodies (Santa Cruz Biotechnology) for $1 \mathrm{~h}$. The slides were stained, dehydrated and cleared and the stained slides were mounted in Permount and visualized using a Nikon Eclipse Ti microscope (Nikon, Tokyo, Japan). Images were captured using an FE330 digital camera (Olympus Corporation, Tokyo, Japan), which was attached to the microscope.

Western blot analysis. The whole cell extracts were prepared and separated by PAGE, as previously described (23-25)
Table I. Expression of Skp2 in hepatocellular carcinorma and paratumor tissues.

\begin{tabular}{lcccc}
\hline & & \multicolumn{2}{c}{ Skp2 } & \\
\cline { 3 - 3 } Tissue & $\begin{array}{c}\text { Sample } \\
\text { no. }\end{array}$ & - & + & $\begin{array}{l}\text { Positive } \\
\text { rate (\%) }\end{array}$ \\
\hline $\begin{array}{l}\text { Hepatocellular } \\
\text { carcinoma }\end{array}$ & 50 & 15 & 35 & $70.0^{\mathrm{a}}$ \\
Paratumor & 40 & 34 & 6 & 15.0 \\
\hline
\end{tabular}

${ }^{\mathrm{a}} \mathrm{P}<0.01$ compared with paratumor tissues. Skp2, S-phase kinase-associated protein 2 .

Table II. Expression of p2 $7^{\mathrm{kip} 1}$ in hepatocellular carcinorma and paratumor tissues.

\begin{tabular}{lcrrr}
\hline & & \multicolumn{2}{c}{$\mathrm{p} 27^{\mathrm{kip} 1}$} & \\
\cline { 3 - 4 } Tissue & $\begin{array}{c}\text { Sample } \\
\text { no. }\end{array}$ & - & + & $\begin{array}{r}\text { Positive } \\
\text { rate }(\%)\end{array}$ \\
\hline $\begin{array}{l}\text { Hepatocellular } \\
\text { carcinoma }\end{array}$ & 50 & 42 & 8 & $16.0^{\mathrm{a}}$ \\
Paratumor & 40 & 4 & 36 & 90.0 \\
\hline
\end{tabular}

${ }^{\mathrm{a}} \mathrm{P}<0.01$ compared with paratumor tissues.

using buffer and gel obtained from Shanghai Qcbio Science and Technologies Co., Ltd. (Shanghai, China) and the machine (Mini-Protean ${ }^{\circledR}$ Tetra Cell) from obtained from Bio-Rad (Hercules, CA, USA). The proteins of the sample were separated using gel electrophoresis and were subsequently transferred to a polyvinylidine difluoride membrane (Millipore, Billerica, MA, USA). Subsequently, blocking of non-specific binding was achieved by placing the membrane in a solution of $5 \%$ bovine serum albumin. Following blocking, a dilute solution of the appropriate primary antibody was incubated with the membrane at $4{ }^{\circ} \mathrm{C}$ overnight. The antibodies used were as follows: Anti-p27, anti-Skp2, anti- $\beta$-actin and horseradish peroxidase-conjugated goat anti-mouse secondary antibody.

MTT assay. An MTT assay was performed, as described previously (26-28). The cells $\left(5 \times 10^{5}\right)$ were seeded into 48 -well plates. Following culture for 24,48 or $72 \mathrm{~h}$, the plates were read on a microplate reader (Varioskan Flash Multimode Reader; Thermo Fisher Scientific, Waltham, MA, USA) at a test wavelength of $490 \mathrm{~nm}$ and a reference wavelength of $570 \mathrm{~nm}$.

Immunoprecipitation. Immunoprecipitation was performed, as previously described (29-31). The cells were lysed and the sample was passed over beads alone or bound to a relevant antibody to absorb any proteins that non-specifically bind to the immunoprecipitation components. For immunoprecipitation analysis, the samples were immunoprecipitated with mouse monoclonal hemagglutinin (HA)-tag antibodies 
A

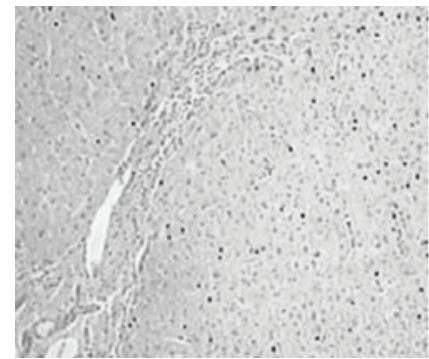

B

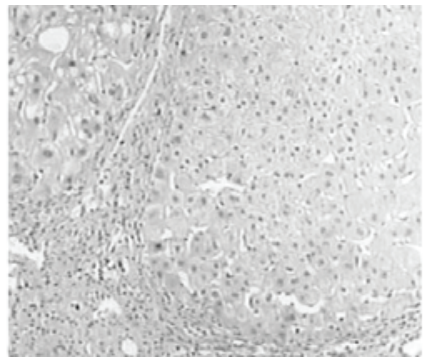

C

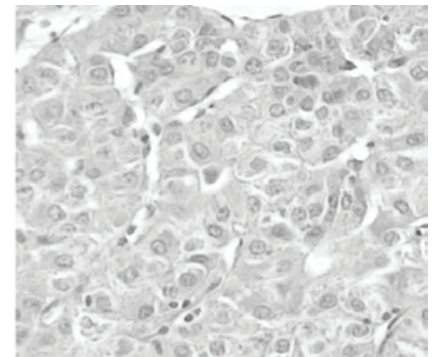

Figure 1. Hematoxylin and eosin staining of the liver tissues in the samples. (A) Image of the normal liver tissues (magnification, x100). (B) Image of the paratumor tissues (magnification, x100). (C) Image of the hepatocellular carcinoma tissues (magnification, $\mathrm{x} 400$ ).
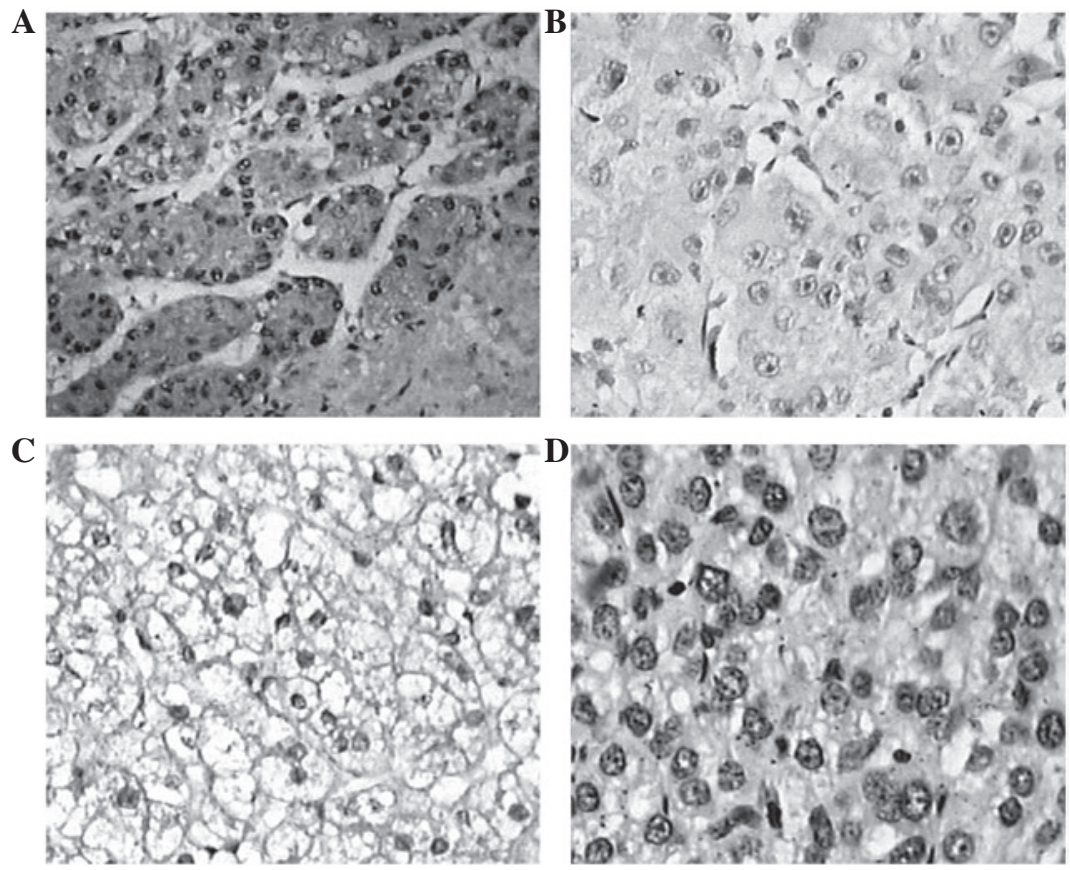

Figure 2. Paraffin-embedded samples were analyzed by histochemical staining of skp2 and p2 $7^{\mathrm{kip} 1}$. (A) Normal expression of p2 $7^{\mathrm{kip} 1}$ in the cell nuclei and cytoplasm of the paratumor tissues (brown staining; magnification, x200). (B) Negative expression of $\mathrm{p} 27^{\mathrm{kip} 1}$ in the hepatocellular carcinoma tissues (magnification, $\mathrm{x} 400$ ). (C) Negative expression of skp2 in the paratumor tissues (magnification, $\mathrm{x} 400$ ). (D) Expression of skp2 in the hepatocellular carcinoma tissues (magnification, x400). Skp2, S-phase kinase-associated protein 2.

(A012244-100; GenScript, Nanjing, China). The immunocomplexes were separated by SDS-PAGE and treated with the secondary antibody. The complexes of Skp2 or ubiquitin with $27^{\text {kipl }}$ were determined by immunoprecipitating the mouse monoclonal anti-Flag antibody (AF519; Beyotime Institue of Biotechnology, Haimen, China) and normalized to the quantity of antibodies. To assess the specificity of the primary antibodies, negative controls were used, in which the antibodies used to immunoprecipitate were incubated for $2 \mathrm{~h}$ at room temperature with the respective immunogen peptide.

FACS analysis. Cell apoptosis rate was determined by Annexin V-fluorescein isothiocyanate (FITC)/ propidium iodide (PI) (Hangzhou Lianke Biology Technology Limited Company, Hangzhou, China) staining. The one-step staining procedure was selected, which takes only $10 \mathrm{~min}$ to perform. Detection was analyzed by flow cytometry (FC 500; Beckman Coulter, Brea, CA, USA), which differentiates between apoptosis and necrosis following Annexin V-FITC and PI staining.

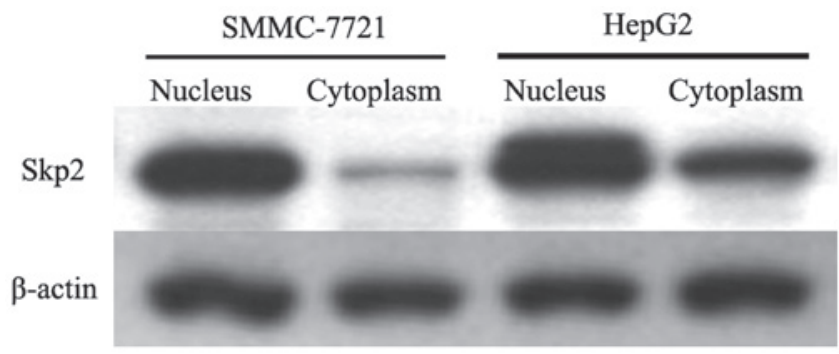

Figure 3. Localization of Skp2 detected by western blot analysis. The SSMC 7721 and HepG2 cells were cultured in 48-well plates, and Skp2 expression levels in the cytoplasm and nucleus were detected by western blot analysis. Skp2, S phase kinase associated protein 2.

Statistical analysis. Student's t-test was used to evaluate statistical significance. Data were analyzed using SPSS 19.0 (IBM SPSS, Armonk, NY, USA) Data are expressed as the mean \pm standard deviation. $\mathrm{P}<0.05$ were considered to indicate a statistically significant difference. 


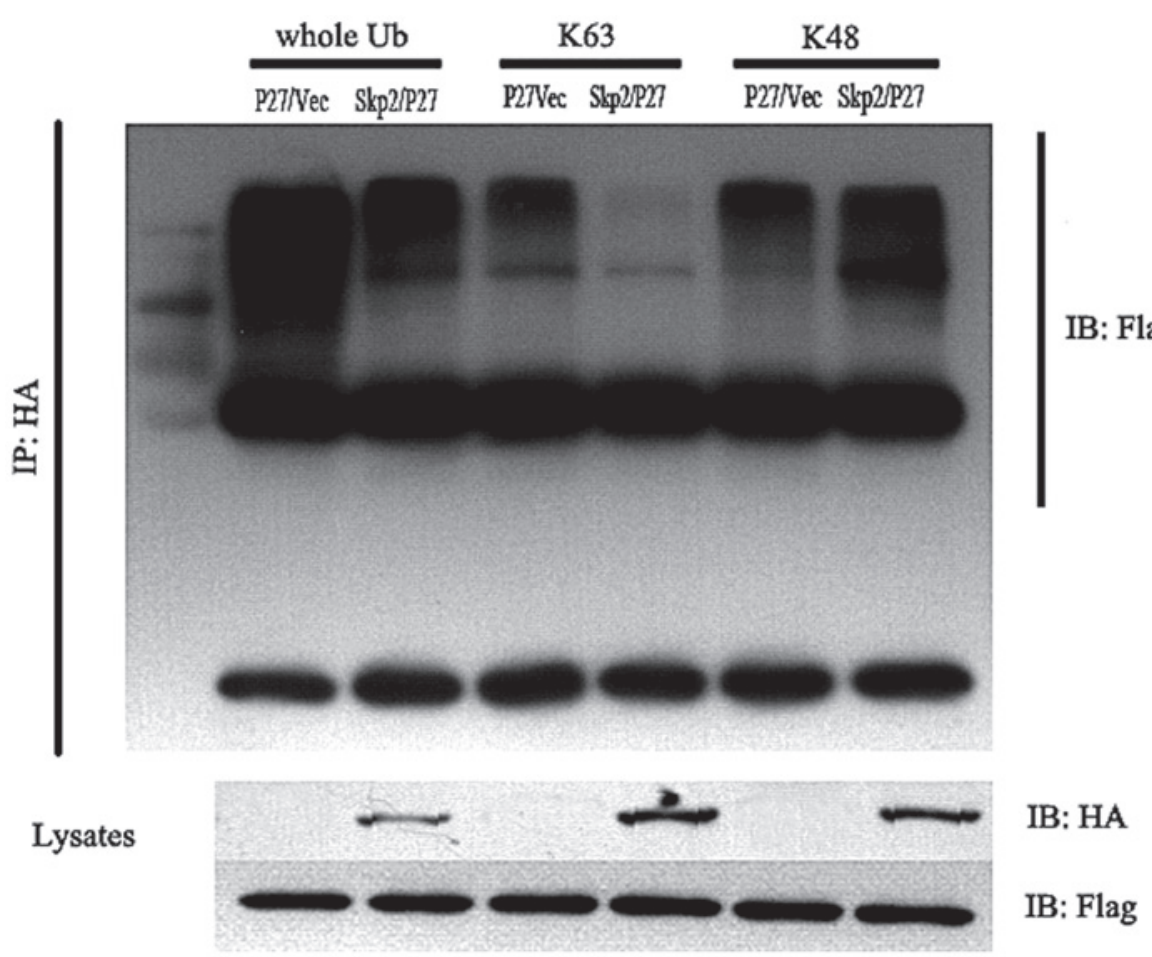

Figure 4. In vivo ubiquitination of P2 $7^{\mathrm{kip} 1}$. HA-Skp2 and Flag-p2 $7^{\mathrm{kip} 1}$ with K48-Ub, K63-Ub or whole Ub, were expressed in the $293 \mathrm{~T}$ cells. After 48 h, the immunoprecipitates obtained using the HA antibodies were immunoblotted for Flag to detect polyubiquitinated p2 $7^{\text {kipl }}$. Skp2, S-phase kinase-associated protein 2; HA, hemagglutinin; Ub, ubiquitin.

\section{Results}

Positive Skp2 staining is observed in the majority of liver cancer tissues. In the present study, 90 registered patients were obtained from the database of Jinan Central Hospital Affiliated to Shandong University. As shown in Fig. 1, H\&E staining of the samples of paratumor liver tissue and hepatocellular carcinoma tissue was compared with normal liver tissues. It is reported that the Skp2-p2 $7^{\mathrm{kip} 1}$ signaling pathway is closely associated with cancer $(32,33)$. In the present study, the expression levels of Skp2 and p27 ${ }^{\mathrm{kip} 1}$ were detected by immunohistochemical analyses in the paratumor and hepatocellular carcinoma tissues. The results revealed that the positive brown staining for Skp2 was predominantly observed in the nuclei with occasional cytoplasmic expression (Fig. 2). Compared with the immnunostaining of the paratumor tissues, nuclear and cytoplasmic localization of Skp2 was observed in the majority of the examined samples in the patients with hepatocellular carcinoma (Table I) with $70.0 \%$ of the malignant tumors demonstrating varying levels of positive immunostaining. A significant difference was observed between the two groups $(\mathrm{P}<0.01)$.

Positive Skp2 staining is limited in hepatocellular carcinoma. The present study then detected the expression and localization of $\mathrm{p} 27^{\mathrm{kip} 1}$ in the hepatocellular carcinoma and paratumor tissues. As shown in Fig. 2, the results of the immunostaining demonstrated that $\mathrm{p} 27^{\mathrm{kip} 1}$ exhibited a primarily nuclear pattern of expression. As shown in Table II, $84.0 \%(42 / 50)$ of the malignant hepatocellular carcinoma tissues demonstrated negative immunostaining; however, negative immunostaining was observed in only
$10 \%(4 / 40)$ of the paratumor tissues, with a significant difference observed between the two groups $(\mathrm{P}<0.01)$.

Localization of Skp2 detected by western blot analysis. In order to confirm the localization of Skp2 in SSMC 7721 and HepG2 cells, cytoplasmic and nucleic proteins were prepared and western blot analysis was performed. As shown in Fig. 3, the results revealed that the majority of Skp2 was located in the nuclei of the cells; although there was low expression detected in the cytoplasm.

Skp2 is degraded by the ubiquitin-proteasome pathway regulated by Skp2. In order to examine whether the degradation of $\mathrm{p} 27^{\mathrm{kip} 1}$ is regulated by Skp2, 293T cells, which expressed HA-Skp2, Flag-p27 and ubiquitin together were used. After 48 h, a co-immunoprecipitation assay was performed and the data demonstrated that the K48-linked p27 ${ }^{\mathrm{kip} 1}$ increased and the K63-linked p27 $7^{\mathrm{kip} 1}$ decreased. The total quantity of ubiquitinated p27 $7^{\mathrm{kip} 1}$ was also downregulated (Fig. 4). Taken together, these data demonstrated that $\mathrm{p} 27^{\mathrm{kip} 1}$ was degraded by the ubiquitin-proteasome pathway, which was mediated by the Skp2 complex.

Interference of Skp2 induces the apoptosis and inhibits the proliferation of SSMC-7721 cells. Skp2 is an oncogene, which is highly expressed in tumor cells. The present study investigated whether interference of Skp2 with specific siRNA induced the apoptosis of liver cancer cells or promoted liver cancer cell death. As shown in Fig. 5, the apoptotic rates of the SSMC-7721 cells transfected with Skp2-siRNA were significantly higher compared with the control cells $(\mathrm{P}<0.01)$. 
A
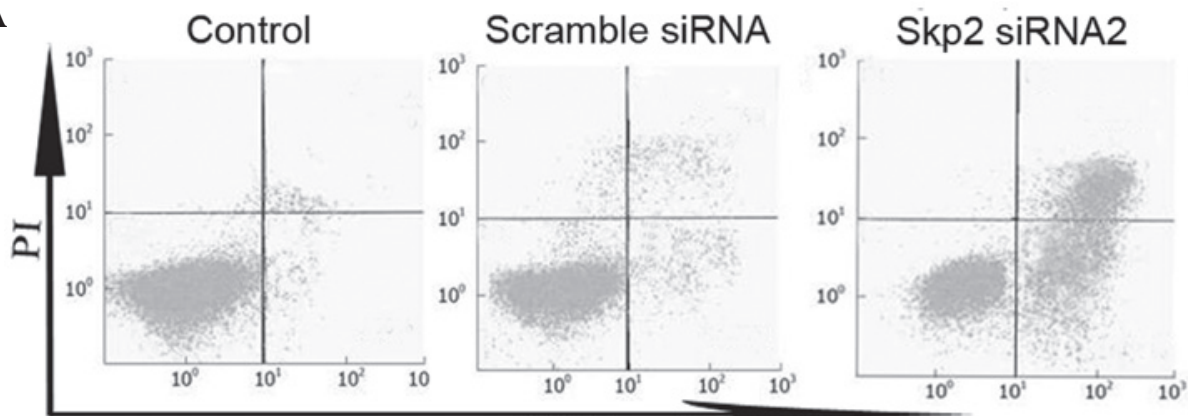

B

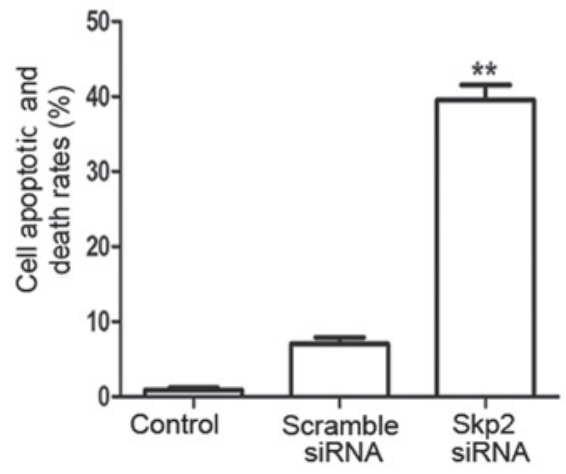

C

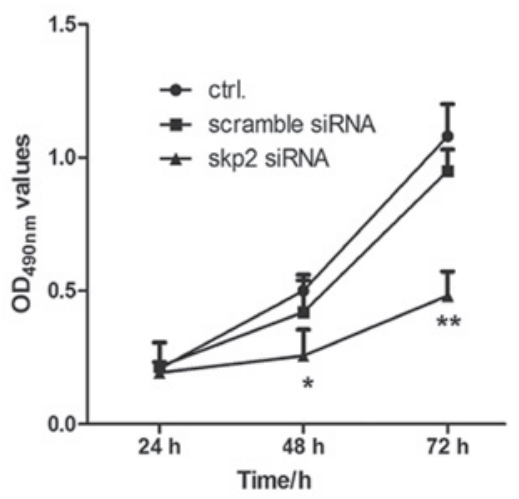

Figure 5. Interference of Skp2 promotes the apoptosis and death of SSMC-7721 cells. (A) Fluorescence-activated cell sorting assay. The SSMC-7721 cells were transfected with Skp2 siRNA. After $48 \mathrm{~h}$, the apoptotic rate was detected by Annexin V-PI staining. The untreated cells and the cells transfected with scramble siRNA were used as negative controls. (B) Histograms of the apoptotic rates by Annexin V-PI staining. ${ }^{* *} \mathrm{P}<0.01$, compared with the negative control cells. (C) MTT assay, in which the cells $\left(5 \times 10^{5}\right)$ were seeded into 48 -well plates and transfected with Skp2 siRNA or scramble siRNA for 24, 48 and $72 \mathrm{~h}$, respectively. Data are expressed as the mean \pm standard deviation of at least three independent experiments on different individuals. ${ }^{*} \mathrm{P}<0.05$ and ${ }^{* * *} \mathrm{P}<0.01$, compared with the control group. Skp2, S-phase kinase-associated protein 2; FITC, fluorescein isothiocyanate; PI, propidium iodide; ctrl, control; OD, optical density.

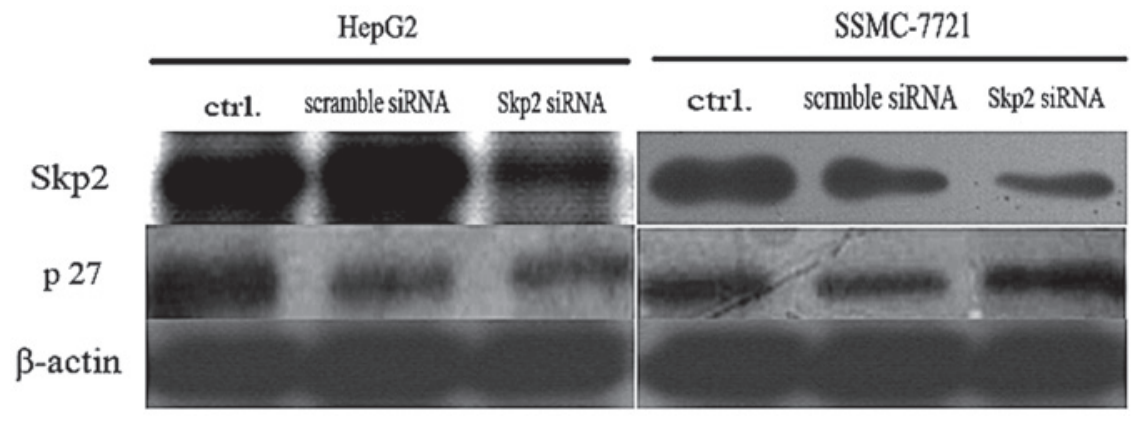

Figure 6. Interference of Skp2 increases the expression of $\mathrm{p} 27^{\mathrm{kip} 1}$. The HepG2 and SSMC-7721 cells $\left(5 \times 10^{5}\right)$ were seeded into 48 -well plates and transfected with Skp2-siRNA for $48 \mathrm{~h}$. Untreated cells (ctrl) or the cells transfected with scramble siRNA were used as negative controls. The expression levels of Skp2, $\mathrm{p} 27^{\mathrm{kip} 1}$ and $\beta$-actin were detected by western blot analysis with $\beta$-actin as an internal reference. Skp2. S-phase kinase-associated protein 2.

In the MTT assay (Fig. 5C), the optical density at $490 \mathrm{~nm}$ in the cells transfected with Skp2-siRNA were significantly lower compared with that of the control cells $(\mathrm{P}<0.05$ and $\mathrm{P}<0.01)$. This was consistent with the results observed by fluorescence-activated cell sorting (FACS), suggesting that the proliferation of cancer cells was inhibited following transfection with Skp2-siRNA.

Interference of the expression of Skp2 increases the expression of $p 27^{k i p l}$. The present study demonstrated that interference of Skp2 induced apoptosis and inhibited proliferation of the SSMC-7721 cells. In order to further examine the mechanism involved and clarify the association with the expression of $\mathrm{p} 27^{\mathrm{kip} 1}$, the expression of $\mathrm{p} 27^{\mathrm{kipl}}$ was examined by western blot analysis. As shown in Fig. 6, following depletion of the expression of endogenous Skp2 by RNA interference, the levels of endogenous $\mathrm{p} 27^{\mathrm{kip} 1}$ increased in the HepG2 and SSMC-7721 cells suggesting that Skp2-mediated degradation of $\mathrm{p} 27^{\mathrm{kipl}}$ was important for proliferation of the tumor cells.

\section{Discussion}

Hepatocellular carcinoma is the fifth most common type of malignant tumor worldwide and the third most common cause of cancer-associated death $(34,35)$. Investigating the 
variation in oncogenes and suppressor genes during hepatocarcinogenesis assists in identifying the prognostic markers of the disease. Regulators controlling the cell cycle, including the $\mathrm{G} 1, \mathrm{~S}$ and $\mathrm{M}$ phases, regulate the progression and development of several types of cancer, including liver cancer $(36,37)$. The present study investigated the clinical predictive value of altered expression levels of p27 $7^{\mathrm{kip} 1}$ and Skp2 in hepatocellular carcinoma tissues compared with normal liver tissues. The results revealed higher expression levels of Skp2, often accompanied by lower expression levels of p27 $7^{\mathrm{kip} 1}$ in hepatocellular carcinoma, which suggested that they may be important in the pathogenesis and progression of liver cancer.

Skp2 is an F-box substrate-recognition subunit in the SCF ubiquitin-protein ligase complex, which is important in degrading the tumor suppressor gene $\mathrm{p} 27^{\mathrm{kip} 1}$ by the ubiquitin-proteasome system (38-42). The present study demonstrated that the expression of $\mathrm{p} 27^{\mathrm{kip} 1}$ was negatively associated with that of Skp2, which was detected by immunohistochemical and western blot analysis. Additionally, the results also demonstrated that interference of Skp2 by Skp2-siRNA significantly inhibited the proliferation of the HepG2 and SSMC-7721 cells, which was detected using an MTT assay and FACS analysis. Decreased levels of Skp2 are usually accompanied by increased levels of $\mathrm{p} 27^{\mathrm{kip} 1}$, which are considered to be associated with the inhibition of cancer cells $(43,44)$. The results of the present study demonstrated that inhibition of hepatocellular carcinoma by interference of Skp2 was mainly dependent on upregulating the protein expression of $\mathrm{p} 27^{\mathrm{kip} 1}$.

$\mathrm{P} 27^{\mathrm{kip} 1}$ degradation is mediated mainly by the ubiquitin-proteasome system and Skp2 is an E3 ligase, one of the major components of the SCF complex. This system specifically recognizes the phosphorylated Thr187 of p27 kip1 and promotes the degradation of $\mathrm{p} 27^{\mathrm{kip} 1}$ by ubiquitination $(30,45)$. When the protein levels of Skp2 decrease, less $\mathrm{p} 27^{\mathrm{kip} 1}$ is recognized and degraded. Thus, accumulation of the tumor inhibitor protein $\mathrm{p} 27^{\mathrm{kip} 1}$ is accompanied by downregulation of Skp2, which was consistent with the results of the MTT and FACS assays in the present study.

In conclusion, the present study confirmed increased expression of Skp2 accompanied by decreased expression of $\mathrm{p} 27^{\mathrm{kip} 1}$ in hepatocellular carcinoma, with the two proteins having a negative correlation. Additionally, the RNA interference technique may provide a novel approach for the therapy and treatment of liver carcinoma.

\section{References}

1. Singh S, Fujii LL, Murad MH, et al: Liver stiffness is associated with risk of decompensation, liver cancer, and death in patients with chronic liver diseases: a systematic review and meta-analysis. Clin Gastroenterol Hepatol 11: 1573-1584, 2013.

2. Tanaka K, Ichikawa Y and Endo I: Liver resection for advanced or aggressive colorectal cancer metastases in the era of effective chemotherapy: a review. Int J Clin Oncol 16: 452-463, 2011.

3. Leenders MW, Nijkamp MW and Borel Rinkes IH: Mouse models in liver cancer research: a review of current literature. World J Gastroenterol 14: 6915-6923, 2008.

4. Coviello E, Caputi G, Martinelli D, Germinario CA and Prato R: Mortality trends for primary liver cancer in Puglia, Italy. Eur J Cancer Prev 19: 417-423, 2010.

5. Shiraha H, Yamamoto K and Namba M: Human hepatocyte carcinogenesis (review). Int J Oncol 42: 1133-1138, 2013.
6. Baillargeon J, Snyder N, Soloway RD, et al: Hepatocellular carcinoma prevalence and mortality in a male state prison population. Public Health Rep 124: 120-126, 2009.

7. Chen JG and Zhang SW: Liver cancer epidemic in China: past, present and future. Semin Cancer Biol 21: 59-69, 2011.

8. Okuda K, Ohtsuki T, Obata H, et al: Natural history of hepatocellular carcinoma and prognosis in relation to treatment. Study of 850 patients. Cancer 56: 918-928, 1985.

9. Lobry C, Oh P, Mansour MR, Look AT and Aifantis I: Notch signaling: switching an oncogene to a tumor suppressor. Blood 123: 2451-2459, 2014.

10. Elliman SJ, Howley BV, Mehta DS, Fearnhead HO, Kemp DM and Barkley LR: Selective repression of the oncogene cyclin D1 by the tumor suppressor miR-206 in cancers. Oncogenesis 3: e113, 2014.

11. Liu Z, Fu Q, Lv J, Wang F and Ding K: Prognostic implication of $\mathrm{p} 27 \mathrm{Kip} 1, \mathrm{Skp} 2$ and Cks1 expression in renal cell carcinoma: a tissue microarray study. J Exp Clin Cancer Res 27: 51, 2008.

12. Newbold A, Salmon JM, Martin BP, Stanley K and Johnstone RW: The role of p21 and p27 in HDACi-mediated tumor cell death and cell cycle arrest in the E $\mu$-myc model of B-cell lymphoma. Oncogene: Dec 2, 2013 (Epub ahead of print). doi: 10.1038/onc.2013.482.

13. Gao J, Zhao Y, Lv Y, et al.: Mirk/Dyrk1B mediates G0/G1 to $\mathrm{S}$ phase cell cycle progression and cell survival involving MAPK/ERK signaling in human cancer cells. Cancer Cell Int 13: 2, 2013.

14. Wei W, Ayad NG, Wan Y, et al: Degradation of the SCF component Skp2 in cell-cycle phase G1 by the anaphase-promoting complex. Nature 428: 194-198, 2004.

15. Bashir T, Dorrello NV, Amador V, Guardavaccaro D and Pagano M: Control of the SCF (Skp2-Cks1) ubiquitin ligase by the APC/C(Cdh1) ubiquitin ligase. Nature 428: 190-193, 2004.

16. Chen G, Wang Y, Garate M, Zhou J and Li G: The tumor suppressor ING3 is degraded by $\mathrm{SCF}(\mathrm{Skp} 2)$-mediated ubiquitin-proteasome system. Oncogene 29: 1498-1508, 2010.

17. Cheng H, Meng J, Wang G, et al: Skp2 regulates subcellular localization of PPARgamma by MEK signaling pathways in human breast cancer. Int J Mol Sci 14: 16554-16569, 2013.

18. Wang Z, Gao D, Fukushima H, et al: Skp2: a novel potential therapeutic target for prostate cancer. Biochim Biophys Acta 1825: $11-17,2012$.

19. Wei Z, Jiang X, Qiao H, et al: STAT3 interacts with Skp2/p27/p21 pathway to regulate the motility and invasion of gastric cancer cells. Cell Signal 25: 931-938, 2013.

20. Pateras IS, Apostolopoulou K, Koutsami M, et al: Downregulation of the KIP family members p27 (KIP1) and p57 (KIP2) by SKP2 and the role of methylation in p57 (KIP2) inactivation in nonsmall cell lung cancer. Int J Cancer 119: 2546-2556, 2006.

21. Saleem M, Maddodi N, Abu Zaid M, et al: Lupeol inhibits growth of highly aggressive human metastatic melanoma cells in vitro and in vivo by inducing apoptosis. Clin Cancer Res 14: 2119-2127, 2008

22. Adhami VM, Siddiqui IA, Ahmad N, Gupta S and Mukhtar H: Oral consumption of green tea polyphenols inhibits insulin-like growth factor-I-induced signaling in an autochthonous mouse model of prostate cancer. Cancer Res 64: 8715-8722, 2004.

23. Nishitani H, Sugimoto N, Roukos V, et al: Two E3 ubiquitin ligases, SCF-Skp2 and DDB1-Cul4, target human Cdt1 for proteolysis. EMBO J 25: 1126-1136, 2006.

24. Peng L, Xu Z, Zhou Y, et al: Effect of rosiglitazone on cells cycle, apoptosis and expression of Skp2 and p27Kip1 in hepatocellular carcinoma cell line. Zhonghua Gan Zang Bing Za Zhi 18: 148-149, 2010 (In Chinese).

25. Schulman BA, Carrano AC, Jeffrey PD, et al: Insights into SCF ubiquitin ligases from the structure of the Skp1-Skp2 complex. Nature 408: 381-386, 2000.

26. Li Y, Huang W, Huang S, Du J and Huang C: Screening of anti-cancer agent using zebrafish: comparison with the MTT assay. Biochem Biophys Res Commun 422: 85-90, 2012.

27. Sarzaeem A, Zare Mirakabadi A, Moradhaseli S, Morovvati H and Lotfi M: Cytotoxic effect of ICD-85 (venom-derived peptides) on HeLa cancer cell line and normal LK cells using MTT assay. Arch Iran Med 15: 696-701, 2012.

28. Sylvester PW: Optimization of the tetrazolium dye (MTT) colorimetric assay for cellular growth and viability. Methods Mol Biol 716: 157-168, 2011.

29. Liu Y, Wang Y, Cheng C, et al: A relationship between p27 (kip1) and Skp2 after adult brain injury: implications for glial proliferation. J Neurotrauma 27: 361-371, 2010. 
30. Rosner $\mathrm{M}$ and Hengstschläger $\mathrm{M}$ : Tuberin binds $\mathrm{p} 27$ and negatively regulates its interaction with the SCF component Skp2. J Biol Chem 279: 48707-48715, 2004.

31. Hu D, Liu W, Wu G and Wan Y: Nuclear translocation of Skp2 facilitates its destruction in response to TGFbeta signaling. Cell Cycle 10: 285-292, 2011.

32. Foster JS, Fernando RI, Ishida N, Nakayama KI and Wimalasena $\mathrm{J}$ : Estrogens down-regulate p27Kip1 in breast cancer cells through Skp2 and through nuclear export mediated by the ERK pathway. J Biol Chem 278: 41355-41366, 2003

33. Pavlides SC, Huang KT, Reid DA, et al: Inhibitors of SCF-Skp2/Cks1 E3 ligase block estrogen-induced growth stimulation and degradation of nuclear p27kip1: therapeutic potential for endometrial cancer. Endocrinology 154: 4030-4045, 2013.

34. Kudo M: Targeted therapy for liver cancer: updated review in 2012. Curr Cancer Drug Targets 12: 1062-1072, 2012.

35. Montalvo-Jave EE, Villegas-Alvarez F, Montalvo-Arenas CE, et al: Liver transplantation: some advances in liver cancer, live liver donation, and cell transplantation. A literature review. Rev Gastroenterol Mex 74: 341-348, 2009.

36. Shanmugasundaram K, Block K, Nayak BK, et al: PI3K regulation of the SKP-2/p27 axis through mTORC2. Oncogene 32: 2027-2036, 2013.

37. Assoian RK and Yung Y: A reciprocal relationship between $\mathrm{Rb}$ and Skp2: implications for restriction point control, signal transduction to the cell cycle and cancer. Cell Cycle 7: 24-27, 2008.
38. Bashir T, Pagan JK, Busino L and Pagano M: Phosphorylation of Ser72 is dispensable for Skp2 assembly into an active SCF ubiquitin ligase and its subcellular localization. Cell Cycle 9: 971-974, 2010.

39. Calvisi DF, Pinna F, Ladu S, et al: The degradation of cell cycle regulators by SKP2/CKS1 ubiquitin ligase is genetically controlled in rodent liver cancer and contributes to determine the susceptibility to the disease. Int J Cancer 126: 1275-1281, 2010.

40. Wei Z, Jiang X, Liu F, et al: Downregulation of Skp2 inhibits the growth and metastasis of gastric cancer cells in vitro and in vivo. Tumour Biol 34: 181-192, 2013.

41. Wu J, Lee SW, Zhang X, et al: Foxo3a transcription factor is a negative regulator of Skp2 and Skp2 SCF complex. Oncogene 32: 78-85, 2013.

42. Wu L, Grigoryan AV, Li Y, et al: Specific small molecule inhibitors of Skp2-mediated p27 degradation. Chem Biol 19: 1515-1524, 2012.

43. Zheng XY, Ding W, Xie LP and Chen ZD: Correlation of Skp2 and P27kip1 protein expression and clinicopathological features of prostate cancer. Ai Zheng 23: 215-218, 2004 (In Chinese).

44. Ben-Izhak O, Lahav-Baratz S, Meretyk S, et al: Inverse relationship between Skp2 ubiquitin ligase and the cyclin dependent kinase inhibitor p27Kip1 in prostate cancer. J Urol 170: 241-245, 2003.

45. Radke S, Pirkmaier A and Germain D: Differential expression of the F-box proteins Skp2 and Skp2B in breast cancer. Oncogene 24: 3448-3458, 2005. 